RESIDENT

\& FELLOW

SECTION

Section Editor

Mitchell S.V. Elkind,

MD, MS

David B. FitzGerald, MD

Ann L. Mitchell, MD

Address correspondence and reprint requests to Dr. David B. FitzGerald, Department of Neurology, McKnight Brain Institute, 100 South Newell Drive, L3-100, P.O. Box 100236, Gainesville, FL 32610 0236

dfitzger@massmed.org

\title{
Career Choices: The fellowship search
}

Electing to continue formal medical education through a fellowship is an important career decision. Unlike finding a residency, the process of finding fellowships and the accreditation status of fellowships are not standardized. This article attempts to clarify the advantages and disadvantages of fellowships in neurology, as well as to describe how to learn of subspecialties that offer fellowships, fellowship availability, and accreditation systems.

BACKGROUND After residency, fellowship is often the next step in formal graduate medical education. Approximately $74 \%$ of neurology residents pursue fellowships. ${ }^{1}$ Unlike the process for finding internship and residency positions, the process and timetable for seeking out, interviewing, evaluating, and, finally, selecting a fellowship depend on the type of fellowship and the institution. There is no national match for fellowships, no standardization of fellowship applications, no centralized list of fellowship positions, and no single accreditation body for all fellowships.

Fellowships offer one a competitive edge when applying for private practice positions. In fact, subspecialty fellowship training is often a requirement for private practice or academic positions. Fellowships also offer one a chance to delve into a field and to gain clinical and laboratory experience in a subspecialty area. Many fellowships offer the opportunity to try writing and teaching, thus providing a chance to experience some aspects of academic neurology.

RESOURCES Fellowships are quite varied in their focus, with a wide range of subspecialty training available (see table). Information about fellowship opportunities is available from multiple sources. The American Academy of Neurology (AAN) Web site offers a listing of many fellowships in its Residents \& Students section (www.aan.com/education/fellowships). Fellowships can be selected on the basis of subject matter, state, or keyword. The United Council for Neurologic Subspecialties (UCNS) Web site (www.ucns.org/apps/directory) also has options for selecting programs by topic matter and state. The UCNS was established in 2003 to provide accreditation for some neurologic subspecialties. The goal of this process is to enhance the quality of training in neurologic specialties and the quality of patient care through setting standards for programs. Listings of types of fellowships accredited by the Accreditation Council for Graduate Medical Education (ACGME) can also be found on the ACGME Web site (www.acgme.org/adspublic) reports/accredited_programs.asp). The ACGME Web site includes some of the information found in the "green book" published each year by the American Medical Association (AMA). The online version can be found at the AMA Web site (www.ama-assn.org/ama/pub/category/

2997.html). Some fellowships are not listed on the AAN, ACGME, or UCNS Web site but only on the individual program's Web site.

In addition to online resources, an efficient venue for face-to-face discussion with multiple fellowship programs is the fellowship fair, or career night, usually held on the Monday night of the annual AAN meeting. Fellowship openings are also advertised in mainline or subspecialty journals, e.g., in the Dendrite section of Neurology Today, as well as on some recruitment Web sites.

A more informal means of finding information about the availability of fellowships in a particular area is discussing program availability and suitability in your area of interest with a faculty member who has similar interests. Often, he or she will know of fellowships in that area or of specialists who are looking for fellowship candidates. Fellowships can also be created on an ad

From the Brain Rehabilitation Research Center (D.B.F.), Malcom Randall Veterans Affairs Medical Center, Gainesville, FL; Department of Neurology (D.B.F.), University of Florida, Gainesville; and Department of Neurology (A.L.M.), University of Massachusetts Medical School, Worcester.

Disclosure: The authors report no conflicts of interest. 
Table Types of fellowships available and accreditation status

ACGME-accredited
Clinical neurophysiology
Endovascular surgical neuroradiology*
Neurodevelopmental disabilities
Neuromuscular medicine
Neuroradiology*
Pain management/pain medicine ${ }^{*}$
Sleep medicine
Vascular neurology

\section{UCNS-accredited}

Behavioral neurology and neuropsychiatry

Clinical neuromuscular pathology ${ }^{+}$

Headache medicine

Neurocritical care

Neuro-oncology

Neuroimaging*

Nonaccredited
Advanced clinical neurology
AIDS
Basic research
Dementia/Alzheimer disease
Epilepsy
Geriatric neurology
Movement disorders
Multiple sclerosis
Neuroepidemiology
Neurogenetics
Neuroimmunology
Neuro-ophthalmology
Neuro-otology
Neuropathology
Neuropharmacology
Neurovirology
Rehabilitation

Shown above is a partial listing of neurology fellowship topics, modified from the Accreditation Council for Graduate Medical Education (AGCME) and United Council for Neurologic Subspecialties (UCNS) Web sites. ACGME and UCNS accreditation status is subject to change and is best checked on the Web sites of the ACGME and UCNS, as well as on the Web site of the individual program. Permission to reproduce granted from ACGME, ( 2007 Accreditation Council for Graduate Medical Education.

"Most ACGME neuroradiology fellowships require completion of radiology residency. UCNS accreditation does not require completion of a radiology residency but does require a neurology residency.

$+U C N S$ accreditation requirements are being finalized.

\#In addition to the ACGME-accredited neurology-based fellowship in pain management, other disciplines, e.g., anesthesia and psychiatry, also accredit pain medicine fellowships, which have different application requirements than the neurology-based prerequisites.

hoc basis using overlapping areas of interest between a specialist in a field and an interested resident. In this instance, it is up to the resident to contact the specialist to determine whether a fellowship can be created.

ACCREDITATION AND CERTIFICATION ACcreditation and certification are two different processes. Accreditation applies to a training program, and certification applies to a person. Accreditation of a program signifies that the curriculum, environment, and resources present in the program meet with the requirements of the accrediting body. The term "certified" is used to designate that an individual has met the requirements of one of the member boards of the American Board of Medical Specialties [e.g., the American Board of Psychiatry and Neurology (ABPN)] or the requirements of the UCNS. As an example, a pain medicine fellowship at a particular institution may be accredited by the ACGME. Those who complete the fellowship at that institution and pass the examination offered by the
ABPN are considered to be "diplomates" or board-certified. Another example is behavioral neurology and neuropsychiatry: fellowships in this subspecialty are accredited by the UCNS, which also certifies neurologists as being diplomates in behavioral neurology and neuropsychiatry.

Fellowships are broadly classed into ACGMEaccredited programs and non-ACGME-accredited programs. ACGME-accredited programs provide a mechanism for non-permanent resident aliens to be employed with a J-1 visa through sponsorship by the Educational Commission for Foreign Medical Graduates (ECFMG). UCNS accreditation of a fellowship does not result in ACGME accreditation. The ECFMG can also sponsor J-1 visas for nonACGME-accredited fellowships, but the details of this process are beyond the scope of this article. Additional information can be found on the ECFMG Web site (www.ecfmg.org), the U.S. Department of State Web site for exchange visitors (http://exchanges.state.gov/education/jexchanges), and the U.S. 
Department of State Web site for J visas (http:// travel.state.gov/visa/temp/types/types_1267.html). Many educational institutions also have sections on their Web sites that provide information about the details of the visa process.

There are no clear-cut guidelines for choosing between accredited or nonaccredited fellowships within a subspecialty. It may be that accredited fellowships are more important for those interested in academic careers than those interested in private practice, but the role of accreditation and uses of accreditation in subspecialties is still evolving. It may be that non-ACGME program graduates will experience problems with hospital privileges and reimbursement. This is best discussed with a mentor and with those in the subspecialty. Both ACGME- and UCNS-accredited fellowships have work-hour requirements that may not always be followed in nonaccredited fellowships.

THE SEARCH PROCESS Initiation of the fellowship search is best started in the beginning of the second year of neurology residency, typically the third postgraduate year. It can be helpful to identify a mentor or advisor who can provide suggestions about programs to apply to and help with timelines for preparation. Preparation of a curriculum vitae (CV) and development of a list of programs of interest should be done in the winter of the same academic year, with letters going out shortly after that. Interviews are often scheduled for highly competitive fellowships in the early spring, with a complete application package having been submitted by March. The timing of the application process is very dependent on the type of fellowship, with highly competitive fellowships often having earlier deadlines than those mentioned above. Once one has decided on an area to pursue, one should contact programs directly because an institution's Web site may or may not have current information about application timelines.

CVs should be prepared carefully because the letter requesting an interview and the CV are typically the two documents used to start the application process. The $\mathrm{CV}$ and cover letter form the basis for initial consideration and should be reviewed by several people for advice. One's advisor and a specialist in the selected field of interest within one's residency department are helpful resources to ensure that there are no errors of omission or commission, and that the emphasis of the $\mathrm{CV}$ is optimal.

After initial consideration of the CV, usually three letters of recommendation are requested by the program. Preparation of these letters is best done early in the fellowship search cycle. Creation of letters of recommendation can be a slow process. The process is helped by giving the requested letter-writers a CV to act as a framework, as well as specific accomplishments that one wishes the author to highlight. The more "prework" done for the writers of letters of recommendation, typically the faster the letters will appear. With the request for a letter of recommendation, one should also submit the names, addresses, phone numbers, and types of programs to which one is applying. Not all fellowship programs require a personal statement, but should a personal statement be required, it should be given to the letter-writers as well so that the letters of recommendation align with the goals of the applicant. If the fellowship does not require a personal statement, applicants should consider writing one in order to assist the letter-writers. Fellowship directors want to hear from individuals who know applicants well.

Letters of recommendation and CVs will only result in an interview, not a job offer. Job offers are driven by the results of the interview. The interview is a reciprocal process, with the applicant learning directly about the program and the fellowship director learning about the applicant. Preparation through careful reading of the Web site, recent publications from the program, and discussion with mentors is essential. Having a list of questions about the program prepared in advance is essential to gathering information to ensure a good experience once in the program. Items for discussion on the day of the interview should include the source of funding for the fellowship, the division of time between clinic and research, a typical week's schedule, the call schedule, if applicable, and the timetable for a decision. The timing of a decision is critical given the asynchronous nature of the interview process. One should ask what the timing for a decision is on the part of the program as well as ask for time to make a decision should one receive an offer.

One should carry copies of one's CV and letters of recommendation. Ideally, one should know the names of the interviewers before arriving at the interview. During the interview, one should meet the current fellow(s), attend conference, and see the overall facility. At the end of the interview, one should have a good idea of the program's expectations, and the program should have a good idea of the interviewee's expectations. After the interview, one should write a 
post-interview "thank you" note, listing the specifics of why the position is of interest and what one could bring to the program.

An interviewee should be concerned if there is a requirement for a full license because this can be driven by the need for the fellow to bill for services as part of the program's revenue stream. In such situations, the emphasis may quickly become on revenue generation rather than research or training. Disorganized interview logistics or confusion about the components of the fellowship should also raise concerns because the interview is the program's opportunity to impress the candidate. High-profile fellowship directors may travel extensively, leading to limited contact and limited educational opportunities.

In addition to face-to-face interviews, discussion with recent graduates of the fellowship may help provide direct and frank opinions about the program. Fellowship directors should be willing to provide the names of those who have been in the program.

Having completed interviews, and hopefully with multiple offers in hand, one should next consider which fellowship is most consistent with one's career goals. Discussion with one's advisor or other mentors can be helpful in this process.

Receipts collected during the interview process should be saved because the job search and relocation process are largely tax-deductible. Finally, one must be on one's best behavior at all times because the subspecialty community in neurology is quite small. Unless there are extreme extenuating circumstances, it is unprofessional for an applicant to accept a position and then renege on that promise and take a more desirable position.

CONCLUSION The current neurology fellowship search process is different than the neurology residency match process. Those wishing to pursue a fellowship should engage in intensive information gathering and consultation, interview early, and be aware of the differences in accreditation between neurologic subspecialties and within subspecialties to maximize the likelihood of getting the fellowship they want and to maximize their career opportunities.

\section{ACKNOWLEDGMENT}

The authors thank Marilyn Leeds, Todd Bulson, David Chad, MD, and Larry D. Sulton, PhD, for their assistance.

\section{REFERENCE}

1. Larson WL, Holloway RG, Keran CM. Employmentseeking experiences of residents in 1996. Neurology 2000;54:214-218 


\section{Neurology}

Career Choices: The fellowship search

David B. FitzGerald and Ann L. Mitchell

Neurology 2008;70; 5 -e8

DOI 10.1212/01.wnl.0000299608.57399.fb

\section{This information is current as of July 16, 2008}

\section{Updated Information \&} Services

References

Permissions \& Licensing

Reprints including high resolution figures, can be found at: http://n.neurology.org/content/70/2/e5.full

This article cites 1 articles, 1 of which you can access for free at: http://n.neurology.org/content/70/2/e5.full\#ref-list-1

Information about reproducing this article in parts (figures,tables) or in its entirety can be found online at:

http://www.neurology.org/about/about_the_journal\#permissions

Information about ordering reprints can be found online: http://n.neurology.org/subscribers/advertise

Neurology ${ }^{\circledR}$ is the official journal of the American Academy of Neurology. Published continuously since 1951, it is now a weekly with 48 issues per year. Copyright . All rights reserved. Print ISSN: 0028-3878. Online ISSN: 1526-632X.

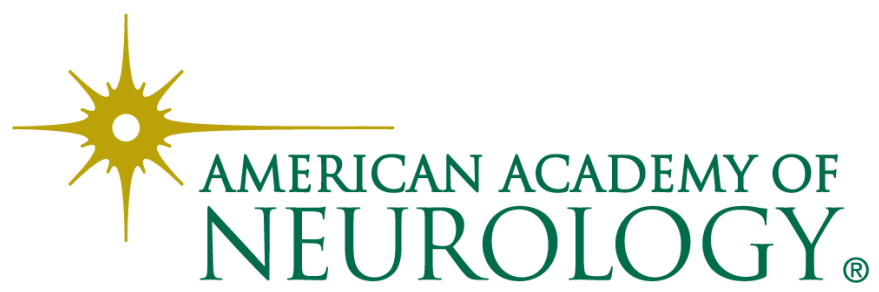

